\title{
Anthocyanins and antioxidant activity of Lonicera caerulea berry wine during different processes
}

\author{
Jiayuan $\mathrm{LUO}^{1 \dagger}$ (D), Ziluan FAN ${ }^{1 \dagger}$, Xue YANG ${ }^{1 \dagger}$, Yi-hong BAO ${ }^{1,2 *}$, Min LIANG ${ }^{1}$, Yang GUO ${ }^{1}$
}

\begin{abstract}
This study aimed to evaluate the effects of seven stages (Lonicera caerulea berry juice, after enzymatic hydrolysis, sugar and acid adjustments, fermentation, deacidification, clarification and ageing) in the making of Lonicera caerulea berry wine on the anthocyanins and antioxidant capacity were studied. The total anthocyanin content was determined by the $\mathrm{pH}$-differential method. The composition of anthocyanins was measured by HPLC-MS/MS. The 1,1-diphenyl-2-picrylhydrazyl (DPPH), 2,2'-azinobis (3-ethylbenzothiazoline- 6-sulphonic acid) (ABTS), ferric reducing potential (FRAP), total antioxidant capacity and cupric ion reducing antioxidant capacity assays were used to measure the antioxidant activities. Eight anthocyanins namely, cyanidin-3-hexoside derivatives, cyanidin-3-acetylhexoside, cyanidin-3-glucoside, peonidin-3-rutinoside, peonidin-3,5dihexoside, peonidin-3-glucoside, cyanidin-3,5-dihexoside and pelargonidin-3-glucoside were detected in Lonicera caerulea berry wine and in all samples taken from each of the brewing processes. Addition of pectinase significantly increased the anthocyanin content by $69.04 \%$ and the peak areas of the individual anthocyanins increased, except for peonidin-3,5-dihexoside and peonidin-3-rutinoside. Although the anthocyanin content decreased throughout the entire process, each sample showed good antioxidant capacity.
\end{abstract}

Keywords: Lonicera caerulea berries, fruit wine, brewing, anthocyanins, antioxidant activity.

Pratical Application: Quality control of anthocyanin components in fruit wine processing.

\section{Introduction}

Lonicera caerulea berry (blue honeysuckle) is a perennial deciduous shrub of the Caprifoliaceae family that is found in the Kamchatka Peninsula (the Russian Far East) (Grobelna et al., 2019). At present, the plant is widely distributed in Russia, Canada, China and Japan. The fruits of the plant are dark blue, fleshy berries that are oval to long in shape (Bao et al., 2019). Previous studies have shown that there are various nutrients, including sugars, organic acids (Lee, Dreves et al., 2015), amino acids, minerals (Boyarskikh et al., 2016), and vitamins, in the fruits. In addition, the berries are a rich source of some active substances, particularly low-molecular-weight phenolic acids, flavonoids and anthocyanins (Zhang et al., 2019; Sharma \& Lee 2021), which have a positive impact on human health as antioxidant, anti-inflammatory, DNA-protective, and antitumour activities(Vilkickyte et al., 2020; Svobodová et al., 2009; Wu et al., 2017; Zdarilova et al., 2010). Due to their nutrients and health benefits, the berries are not only consumed fresh but also widely used for the production of juice, wine, jams, candies, puffed snacks, juice concentrate, canned fruit, tea and frozen fruit (Gawronski et al., 2020; Liu et al., 2009; Liu et al., 2010; Skupien et al., 2007).

Colour is one of the most important sensory properties of foods. Dietary consumption of fruits or vegetables rich in anthocyanins is associated with some health benefits, such as inhibition of thrombus (Santhakumar et al., 2015), reduction of arterial stiffness (Jennings et al., 2012; Qiu et al., 2016), and reduction of risks associated with cardiovascular disease (Cassidy, 2017; Pascual-Teresa, 2014; Kruger et al., 2014). However, studies have shown that anthocyanins are unstable and are affected by various factors, including $\mathrm{pH}$, temperature, enzymes, light, sugars, degradation products, metal ions, sulfur dioxide, oxygen and fermentation strains, but among these, $\mathrm{pH}$ is the most important factor (Fischer et al., 2013). When the $\mathrm{pH}$ is less than 3, anthocyanins, which are present as flavylium cations, are highly stable and bright red in colour, but as the $\mathrm{pH}$ increases, they generally become colourless pseudobases, colourless chalcones and blue quinoidal bases (Pereira-Caro et al., 2000).

Current research on blue honeysuckles is mainly focused on the extraction and analysis of their anthocyanins (Myjavcová et al., 2010; Celli et al., 2015), comparisons of the anthocyanins in various blue honeysuckles (Wang et al., 2016a), and determining the biological functions of blue honeysuckle extract (Wang et al., 2016b; Wang et al., 2017). Due to the difficulties in storing fresh fruits of blue honeysuckle, they are processed into a variety of products, including juice, jams and wine. Although anthocyanins in fruits are affected by different processing techniques and certain 
links between the consumption of some fermented alcoholic beverages and health have been reported (Gorinstein et al., 2000), studies on the effects of alcoholic fermentation on the anthocyanins in blue honeysuckle and their antioxidant activity are not as common. Fermentation can enhance the nutritional value of food. Moderate consumption of fruit wine will increase the body's absorption of a variety of compounds with strong antioxidant capacity. The demand for trace elements such as $\mathrm{Ca}, \mathrm{Co}, \mathrm{K}, \mathrm{Fe}$, and $\mathrm{Zn}$ brings health benefits.

Lonicera caerulea has a short picking period and can mature in a large area in a short period of time, resulting in overproduction. Due to large natural temperature fluctuations, improper picking process handling, improper storage facilities, inconvenient transportation or microbial infections, etc., the fruit will rot and deteriorate. Therefore, the use of ripe fruit or its juice to produce fruit wine is one of the effective ways to improve the value of the original fruit. In this study, the changes in the anthocyanin content and composition during the Lonicera caerulea wine making processes were studied by HPLC-MS/MS. The seven stages of winemaking included Lonicera caerulea juice, enzymatic hydrolysis, sugar and acid adjustments, fermentation, deacidification, clarification and ageing. The 1,1-diphenyl-2picrylhydrazyl (DPPH), 2,2'-azinobis (3-ethylbenzothiazoline6-sulphonic acid) (ABTS), ferric reducing potential (FRAP), total antioxidant capacity (TOAC), and cupric ion reducing antioxidant capacity (CUPRAC) assays were used to evaluate the antioxidant activity.

\section{Materials and methods}

\subsection{Chemicals and reagents}

Pectinase, ABTS ( $\geq 98 \%$ ), new copper reagent (neocuproine,Used as a reagent for the determination of cuprous), 2,4,6-tripyridyltriazine (TPTZ) (BR, 98\%), formic acid, DPPH and methanol were obtained from Yuanye Biological Technology Co., Ltd (Shanghai, China). Medium-baked oak chips and heavily toasted oak chips were purchased from Xingdu Oak Trading Company (Changchun, China). The active dry wine yeast was purchased from Angel Yeast Co., Ltd. Other chemicals and reagents were of analytical grade and were obtained from Tianli Chemical Reagents Co., Ltd (Tianjin, China).

\subsection{Plant material}

Lonicera caerulea berries were harvested in Heihe City $\left(50^{\circ} 14^{\prime} 36.66^{\prime \prime} \mathrm{N}, 127^{\circ} 31^{\prime} 15.89^{\prime \prime} \mathrm{E}\right)$, Heilongjiang Province, China, in June 2020. The fresh blue honeysuckle harvested by mechanicial picking were packed in PE plastic boxes and stored at $-20{ }^{\circ} \mathrm{C}$ until use. The berries were elongated in shape with a longitudinal diameter of approximately $2 \mathrm{~cm}$ and a single fruit weight of up to $1.13 \mathrm{~g}$. The fruits were blue-purple in colour, and the fruit tasted sour and slightly astringent.

\subsection{Enzymatic hydrolysis}

Lonicera caerulea berries were sorted to remove immature fruits and leaves. The fruits were homogenised by JJ-2 Tissue disintegrator. The mixture was adjusted $50{ }^{\circ} \mathrm{C}$ for
$200 \mathrm{~min}$, added $0.10 \%$ pectinase, Then, placed in a $95{ }^{\circ} \mathrm{C}$ water bath for $5 \mathrm{~min}$. After enzymatic hydrolysis, the pulp was centrifuged by desk centrifuge at $4000 \mathrm{r} / \mathrm{min}$ for $10 \mathrm{~min}$ to remove the blue honeysuckle pomace (Guo et al., 2018; Toy et al., 2020). The supernatant was used to determine the anthocyanin content and anthocyanin composition. The remaining fruit pulp containing the pomace was used for the next test.

\subsection{Sugar and acid adjustments}

Before fermentation, the composition of the blue honeysuckle pulp must be adjusted to make the environment suitable for yeast growth and reproduction. In this experiment, the sugar content and $\mathrm{pH}$ of the pulp were adjusted. To obtain Lonicera caerulea berry wine with $10 \%$ alcohol by volume, the sugar content of the pulp was determined; the sugar content (3.31\%) of the pulp was then adjusted by sucrose according to Bryce Rankine's method (Mason, 2013) for brewing high-quality wines, that is, $18.39 \mathrm{~kg}$ of sucrose was added for every 100 $\mathrm{L}$ of pulp. To prevent the yeast from being exposed to high osmotic pressure, the sugar was added in two batches, on the first and fourth days. Each batch contained $9.20 \mathrm{~kg}$ of sucrose. In addition, the $\mathrm{pH}$ of the fruit pulp was adjusted to 3.2 by $10 \%$ sodium bicarbonate solution. Then, $5 \mathrm{~g} / 100 \mathrm{~L} \mathrm{SO}_{2}$ was added. The mixture was placed at room temperature for 6-8 $\mathrm{h}$ to prevent the sulfur dioxide from interfering with the growth of the strain.

\subsection{Fermentation}

Active dry wine yeast from Angel was used as the fermentation strain. The yeast was activated in a $5 \%$ aqueous sucrose solution in $40^{\circ} \mathrm{C}$ for $30 \mathrm{~min}$, and activation yeast was inoculated into the pulp to give a final concentration of $0.15 \%$. After inoculation, the broth was placed in a $26^{\circ} \mathrm{C}$ constant temperature incubator for 12 days until the weight of the fermentation broth was constant. The mixture was centrifuged to remove fruit residues. Then, the fruit wine was kept at $4{ }^{\circ} \mathrm{C}$ until the next assay.

\subsection{Deacidification, clarification and ageing of the wine}

Blue honeysuckle is a kind of berry with high acidity. The wine brewed in this test had $16.40 \pm 0.12 \mathrm{~g} / \mathrm{kg}$ of total acid, so deacidification was necessary. Berry wine with a total acidity of $7.35 \pm 0.20 \mathrm{~g} / \mathrm{kg}$ was obtained by adding $2 \mathrm{~g} / \mathrm{L}$ calcium carbonate and $4 \mathrm{~g} / \mathrm{L}$ sodium carbonate, and the mixture was incubated at room temperature for one day. Then, $2.0 \mathrm{~g} / \mathrm{L}$ chitosan solution ( $1 \mathrm{~g}$ of chitosan and $1 \mathrm{~g}$ of citric acid were dissolved in $98 \mathrm{~g}$ of water) was used as a clarifying agent. After $24 \mathrm{~h}$ of clarification at $4{ }^{\circ} \mathrm{C}$, the wine was centrifuged to remove precipitates. Taking distilled water as a reference, the absorbance at $660 \mathrm{~nm}$ is expressed by $\mathrm{T} \%$, and the higher the light transmittance, the better the clarity. Then, the clarified wine was aged in the dark at room temperature for six months. The samples from each stage used for the analysis of the anthocyanins were centrifuged at $4000 \mathrm{r} / \mathrm{min}$ for $10 \mathrm{~min}$ (Li et al., 2009). 


\subsection{Total anthocyanin content analysis}

The anthocyanins were determined by the $\mathrm{pH}$-differential method according to Denev (Denev et al., 2014). The absorptions of the sample were measured at $\mathrm{pH} 1.0$ and $\mathrm{pH} 4.5$, and the difference in the absorbance is proportional to the anthocyanin content. A $1 \mathrm{~mL}$ sample and $9 \mathrm{~mL}$ of $\mathrm{pH} 1.0$ or $\mathrm{pH} 4.5$ buffer were mixed and placed in the dark for $20 \mathrm{~min}$ at room temperature. Then, the absorbance of the sample was measured at $510 \mathrm{~nm}$ and at $700 \mathrm{~nm}$. The results were calculated by the following formula:

anthocyanin content $(\mathrm{mg} / \mathrm{L})=(\Delta \mathrm{A} \times \mathrm{Mw} \times \mathrm{DF} \times 1000) /(\varepsilon \times \mathrm{L})$

where $\Delta \mathrm{A}=\left(\mathrm{A}_{510 \mathrm{~nm}} \mathrm{pH} 1.0-\mathrm{A}_{700 \mathrm{~nm}} \mathrm{pH} 1.0\right)-\left(\mathrm{A}_{510 \mathrm{~nm}} \mathrm{pH} 4.5\right.$ $\mathrm{A}_{700 \mathrm{~nm}} \mathrm{pH}$ 4.5); DF is the dilution factor; $\mathrm{M}_{\mathrm{W}}$ is the molecular weight of cyanidin-3-glucoside (449.2); $\varepsilon$ is the molar absorptivity of cyanidin-3-glucoside (26900); L is the pathlength of the cell (usually $1 \mathrm{~cm}$ ).

\subsection{Anthocyanin composition analysis}

All samples were centrifuged at $6000 \mathrm{r} / \mathrm{min}$ for $15 \mathrm{~min}$, and the supernatant was filtered through a $0.22 \mu \mathrm{m}$ filter and stored at $-4{ }^{\circ} \mathrm{C}$ until analysis. The anthocyanins were analysed by liquid chromatography-mass spectrometry (HPLC-MS). A UHPAQ $\mathrm{C}_{18}$ column $(2.1 \times 50 \mathrm{~mm}, 1.9 \mu \mathrm{m})$ was used at $27^{\circ} \mathrm{C}$. The injection volume of the sample was $5 \mu \mathrm{L}$. A $0.1 \%$ formic acid solution (A) and methanol (B) were used as the mobile phases. The elution program was as follows: $0 \mathrm{~min}, 85 \% \mathrm{~A} ; 1-2 \mathrm{~min}, 50 \% \mathrm{~A}$; and 4-6 $\mathrm{min}, 20 \% \mathrm{~A}$. The flow rate was $0.30 \mathrm{~mL} / \mathrm{min}$.

The anthocyanins were identified using a 6430 series quadruple mass spectrometer in positive ionisation mode for analysing ions and the scanning range was $400-1000 \mathrm{~m} / \mathrm{z}$. The drying gas was nitrogen (capillary temperature $300^{\circ} \mathrm{C}$, capillary voltage $4 \mathrm{kV}$, dry gas pressure 15 psi and flow rate $11 \mathrm{~L} / \mathrm{min}$.), and the nebuliser pressure was set to $41.3 \mathrm{kPa}$. ESI-MS parameters (positive mode): capillary, $4500 \mathrm{~V}$; end plate, $4000 \mathrm{~V}$; cap exit, +90 V; cap exit offset, +60 V; skim 1, +30 V; skim 2,+10 V.

\subsection{Antioxidant activity}

\section{DPPH assay}

The DPPH radical scavenging activity was determined according to the method described by Shen et al. (Shen et al., 2017). DPPH (0.2 mmol/L) was prepared in absolute ethanol and kept in the dark at $4{ }^{\circ} \mathrm{C}$. Ten microliters of different concentrations of ascorbic acid or sample, $990 \mu \mathrm{L}$ of distilled water and $2 \mathrm{~mL}$ of DPPH were mixed and kept in the dark for $30 \mathrm{~min}$. The absorbance of ascorbic acid was measured at $517 \mathrm{~nm}$. The DPPH radical scavenging activity of the sample was calculated as follows:

DPPH radical scavenging activity $(\%)=[1-$ A sample $/$ A control $] \times 100(2)$

A standard curve was constructed with the ascorbic acid concentration as the abscissa and clearance as the ordinate. The results are expressed as $\mathrm{mg}$ ascorbic acid/mL sample.

\section{ABTS assay}

The ABTS free radical scavenging capacity was determined by the method of Zheng et al. with some modifications (Zheng et al., 2018). ABTS (7 mmol/L) and $142 \mathrm{mmol} / \mathrm{L} \mathrm{K}_{2} \mathrm{O}_{8} \mathrm{~S}_{2}$ were mixed in a ratio of 1:1, and the solution was placed in the dark at room temperature for $12 \mathrm{~h}$. The absorbance of the reaction mixture was adjusted to $0.700 \pm 0.01$ at $734 \mathrm{~nm}$ by $20 \mathrm{mM}$ sodium acetate buffer ( $\mathrm{pH} 4.5$ ). A $100-\mu \mathrm{L}$ aliquot of sample was added to $2.9 \mathrm{~mL}$ of the $\mathrm{ABTS}^{+}$solution, and the mixture was kept in the dark for $6 \mathrm{~min}$ at room temperature. The absorbance at $734 \mathrm{~nm}$ was determined by a visible light spectrophotometer. The ABTS radical scavenging activity of the sample was calculated as follows. The final results are expressed as $\mathrm{mg}$ ascorbic acid/mL sample.

ABTS radical scavenging activity $(\%)=[1-$ Asample $/$ Acontrol $] \times 100$

\section{Ferric reducing antioxidant potential assay (FRAP)}

The assay was performed using a modified version of the method described by Vilkickyte et al. (Vilkickyte et al., 2020). The FRAP solution was freshly prepared as follows: $10 \mathrm{mmol} / \mathrm{L}$ TPTZ, $300 \mathrm{mmol} / \mathrm{L}$ acetate buffer $(\mathrm{pH} \mathrm{3.6})$ and $20 \mathrm{mmol} / \mathrm{L}$ $\mathrm{FeCl}_{3} \cdot 6 \mathrm{H}_{2} \mathrm{O}$ were mixed at a ratio of $1: 10: 1(\mathrm{v} / \mathrm{v} / \mathrm{v})$. A $100-\mu \mathrm{L}$ sample was added to $300 \mu \mathrm{L}$ of deionized water and $3 \mathrm{~mL}$ of FRAP solution. After $4 \mathrm{~min}$ in a $37^{\circ} \mathrm{C}$ water bath, the absorbance at $593 \mathrm{~nm}$ was recorded. Iron (II) sulfate solutions were used to construct a standard curve, and the results are expressed as mmol $\mathrm{Fe}^{2+} / \mathrm{mL}$ sample.

\section{Cupric ion reducing antioxidant capacity (CUPRAC)}

Determination of the CUPRAC values was carried out using a modified version of the method described by Ayaz et al. (Ayaz et al., 2017). Neocuproine (10 mM), $7.5 \mathrm{mM} \mathrm{CuCl}_{2}$ and $1 \mathrm{mM}$ ammonium acetate were used for this analysis. A 1-mL aliquot of the diluted sample, $1 \mathrm{~mL}$ of $\mathrm{CuCl}_{2}, 1 \mathrm{~mL}$ of neocuproine and $1 \mathrm{~mL}$ of ammonium acetate were mixed and kept at room temperature for $30 \mathrm{~min}$. The absorbance at $450 \mathrm{~nm}$ was measured. The CUPRAC value of the sample is expressed as mg ascorbic acid/mL sample.

\section{Total antioxidant capacity (TOAC)}

The TOAC was evaluated by the phosphomolybdenum method (Prieto et al., 2015). A 300- $\mu \mathrm{L}$ aliquot of the diluted sample was mixed with $3 \mathrm{~mL}$ of ammonium molybdate mixture $(2.13 \mathrm{~g}$ of sodium phosphate, $0.99 \mathrm{~g}$ of ammonium molybdate and $6.67 \mathrm{~mL}$ of sulfuric acid were dissolved in $200 \mathrm{~mL}$ of distilled water). After $90 \mathrm{~min}$ at $95^{\circ} \mathrm{C}$, the absorbance at $695 \mathrm{~nm}$ was measured. The results are expressed as $\mathrm{mg}$ ascorbic acid/mL sample.

\subsection{Statistical analysis}

The experiments were carried out in triplicate, and the data are expressed as the mean \pm SD. Bar charts were drawn by Origin 8 , and differences were assessed by IBM SPSS Statistics 22. Differences were considered to be statistically significant $(P<0.05)$ and very statistically significant $(P<0.01)$. 


\section{Results and discussion}

\subsection{Evolution of total anthocyanin content (TAC) at different stages of blue honeysuckle wine}

The anthocyanins in blue honeysuckle constantly change during the different stages of winemaking. The effects of different stages of winemaking on the anthocyanin content are shown in Figure 1. The content of anthocyanins was $134.54 \pm 2.07 \mathrm{mg} / \mathrm{L}$ in the blue honeysuckle juice. The content of anthocyanins in the blue honeysuckle juice was increased significantly by pectinase, and the rate of increase was as high as $69.04 \%$. The TAC decreased significantly when the acid and sugar contents were adjusted. The TAC only accounted for $38.13 \%$ of the blue honeysuckle pulp after yeast fermentation. The possible reasons for the decrease in the anthocyanin content are as follows: yeast can adsorb anthocyanins, and its adsorption capacity is related to its own cell wall structure and composition, charge, power distribution and accessible area (Medina et al., 2005); the secondary metabolites released by yeast (such as pyruvate and acetaldehyde) can react with the anthocyanins to form macromolecules (Berenguer et al., 2016; Caridi, 2007). The processes of deacidification, clarification and ageing significantly decrease the content of anthocyanins.

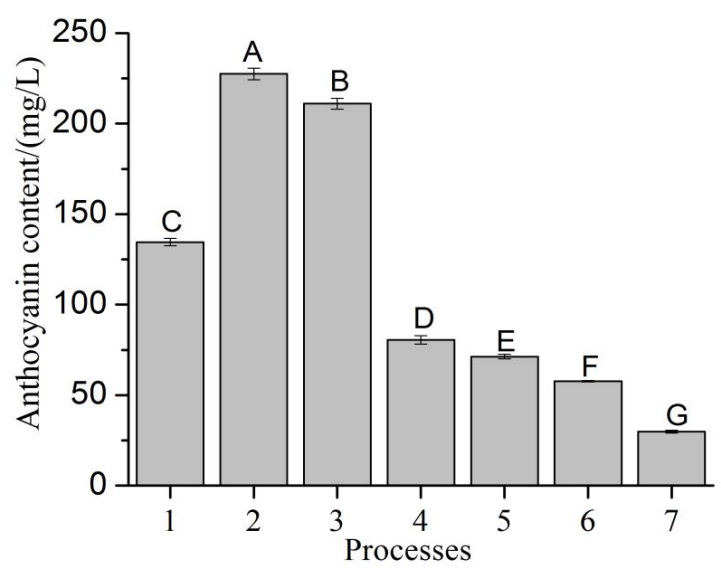

Figure 1. Anthocyanin content at different stages. The numbers 1-7 represent different stages of the process: 1 blue honeysuckle juice (before enzymatic hydrolysis), 2 enzymatic hydrolysis, 3 sugar and acid adjustments, 4 fermentation, 5 deacidification, 6 clarification, 7 ageing. The data are presented as the mean \pm SD. Different capital letters on the bar chart indicate significant differences $(p \leq 0.01)$.

\subsection{Evolution of anthocyanin composition at different stages of blue honeysuckle wine}

The composition of anthocyanins in Lonicera caerulea berry juice was determined by HPLC-MS/MS. The types of anthocyanins and their molecular and fragment ions are shown in Table 1. Eight anthocyanins in the Lonicera caerulea berry juice were identified by analysis of their molecular ions and fragment ions (Myjavcová et al., 2010; Veberic et al., 2015). These anthocyanins are cyanidin-3-hexoside derivatives, cyanidin-3-acetylhexoside, cyanidin-3-glucoside, peonidin-3-rutinoside, peonidin-3,5dihexoside, peonidin-3-glucoside, cyanidin-3,5-dihexoside and pelargonidin-3-glucoside. The fresh blue honeysuckle contains three types of anthocyanidin aglycones, including cyanidins, peonidins and pelargonidins. Among these species, cyanidins are the major compounds, followed by peonidins and pelargonidins. The relative percentage of cyanidin-3-glucoside was the highest, followed by peonidin-3-glucoside, cyanidin-3,5-dihexoside, pelargonidin-3-glucoside, peonidin-3,5-dihexoside, peonidin-3rutinoside, cyanidin-3-acetylhexoside, and cyanidin-3-hexoside.

The effects of different processes during wine brewing on the anthocyanin composition, peak area and relative percentages were studied in detail, and the results are shown in Table 2. The primary mass spectrum of the anthocyanins is shown in Figure 2. As shown in Table 2 (Number 2), the anthocyanin peak areas in blue honeysuckle juice increased due to pectinase hydrolysis. The commercial enzymes based on pectinase are usually heterogeneous mixtures of polygalacturonases, pectin lyases and pectin methylesterases activities. These products hydrolyse the pecto-cellulosic cell walls of the grapes skin improving juice yield (Scutarasu et al., 2021). Except for peonidin-3,5-dihexoside and peonidin-3-rutinoside, the peak areas of the individual anthocyanins increased by factors of 1.03-1.69 upon treatment with pectinase, implying heavy degradation of the pectin in the berry skin and release of the anthocyanins. The degradation of peonidin-3,5-dihexoside and peonidin-3-rutinoside may be due to the reduction of the acyl group in which the pectinase acts.

Before fermentation, the $\mathrm{pH}$ and sugar content of the blue honeysuckle pulp need to be adjusted to provide a suitable environment for yeast growth and reproduction. The effects of adjusting the sugar content and $\mathrm{pH}$ on the anthocyanin composition are shown in Table 2 (Number 3). A decrease in the total peak area of the anthocyanins was found. Except for peonidin-3,5-dihexoside and cyanidin-3,5-dihexoside, the peak areas of the remaining anthocyanins decreased to different extents. Peonidin-3-glucoside and cyanidin-3-glucoside were heavily

Table 1. Anthocyanins types and their molecular and fragment in L. caerulea berry.

\begin{tabular}{|c|c|c|c|}
\hline Anthocyanins types & Molecular/(m/z) & Fragment $/(\mathrm{m} / \mathrm{z})$ & Tentative identification \\
\hline 1 & 737 & 575 & Cyanidin-3-hexoside derivative \\
\hline 2 & 625 & $301 、 463$ & Peonidin-3,5-dihexoside \\
\hline 3 & 611 & 287、 449 & Cyanidin-3,5-dihexoside \\
\hline 4 & 609 & $301 、 463$ & Peonidin-3-rutinoside \\
\hline 5 & 491 & 287 & Cyanidin-3-acetylhexoside \\
\hline 6 & 463 & 301 & Peonidin-3-glucoside \\
\hline 7 & 449 & 287 & Cyanidin-3-glucoside \\
\hline 8 & 433 & 271 & Pelargonidin-3-glucoside \\
\hline
\end{tabular}




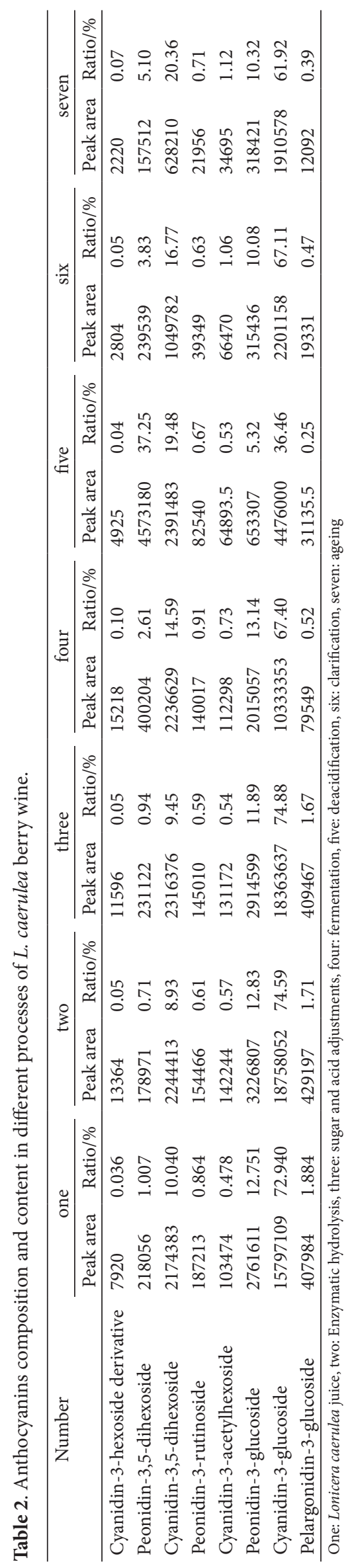




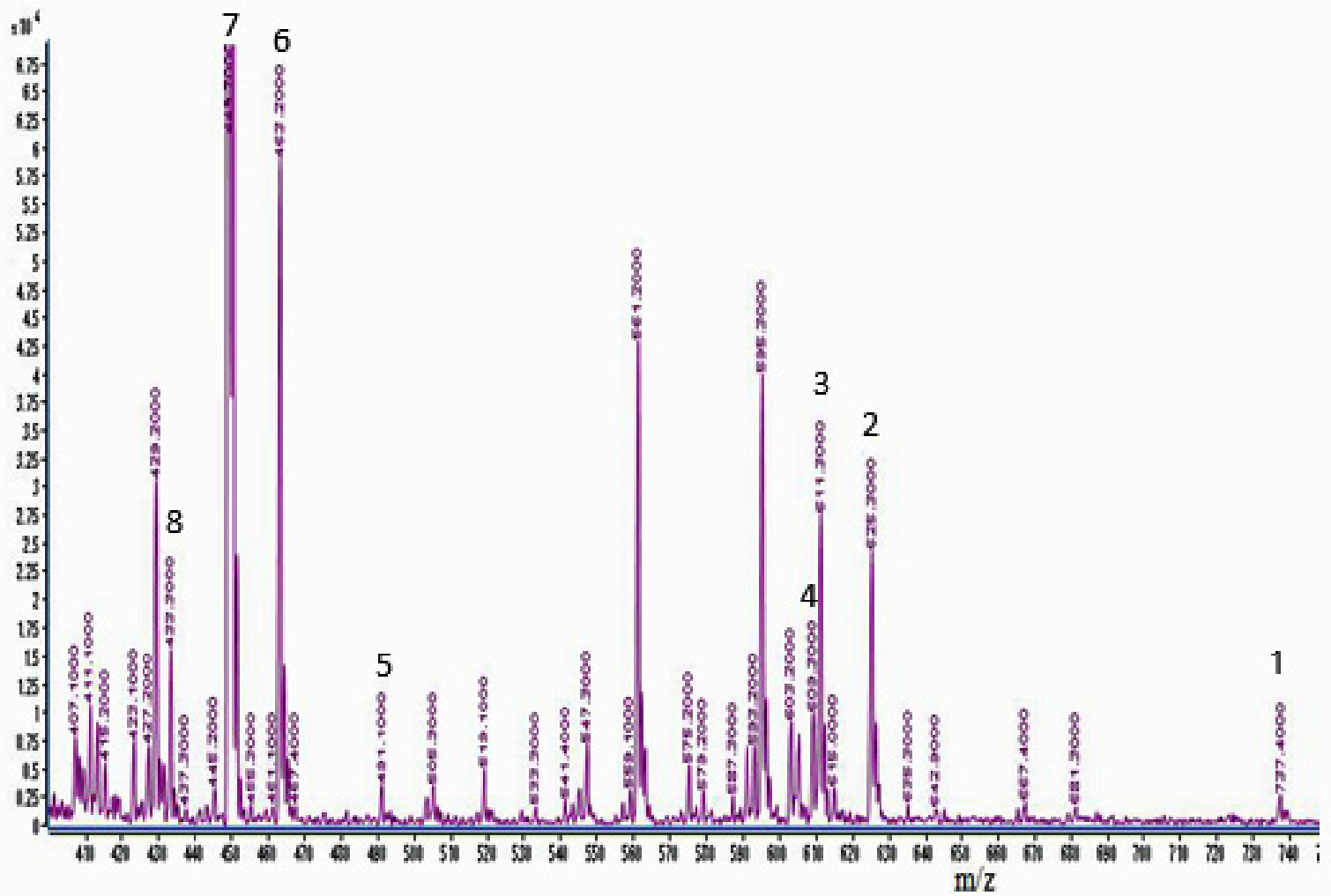

Figure 2. Primary mass spectrum of Lonicera caerulea berry's anthocyanins. 1 Cyanidin-3-hexoside derivative; 2 Peonidin-3,5-dihexoside; 3 Cyanidin-3,5-dihexoside; 4 Peonidin-3-rutinoside; 5 Cyanidin-3-acetylhexoside; 6 Peonidin-3-glucoside; 7 Cyanidin-3-glucoside; 8 Pelargonidin3-glucoside.

affected during this process, and they decreased by 312208 and 394415 , respectively. These two monoglycoside anthocyanins likely reacted with the acids and microbial enzyme to produce the corresponding bisglycoside anthocyanins, resulting in the observed decrease.

Fermentation is a complicated process. During this process, the total acid value and alcohol content gradually increase, and the total sugar content decreases. The effect of yeast fermentation on the anthocyanin composition is shown in Table 2 (Number 4). Substantial decreases in the total peak area (by $37.48 \%$ ) were observed. The peak areas of the cyanidin-3-hexoside derivative and peonidin-3,5-dihexoside increased by $31.23 \%$ and $73.15 \%$, respectively. The other six anthocyanins decreased to different extents, especially peonidin-3-glucoside, cyanidin-3-glucoside and pelargonidin-3-glucoside, which decreased by $30.80 \%$, $43.73 \%$ and $80.57 \%$, respectively. The fermentation results showed that the contents of monoglycoside anthocyanins decreased dramatically, but the contents of bisglycoside anthocyanins and anthocyanin derivatives substantially increased.

Titratable acidity has an important impact on the flavour of wine, and improper acidity can affect wine quality (Berenguer et al., 2016). The influence of deacidification on the anthocyanin composition is shown in Table 2 (Number 5). Eight anthocyanins remained in the deacidified sample, but the total peak area decreased by $19.92 \%$. The peak areas of peonidin3,5-dihexoside and cyanidin-3,5-dihexoside tended to increase, especially that of peonidin-3,5-dihexoside, which increased by a factor of 10.42. The peak areas of the remaining anthocyanins decreased by $41.05 \%-67.63 \%$ probably because the addition of calcium carbonate and sodium carbonate increases the $\mathrm{pH}$.

Chitosan is a common clarifying agent. The transmittance of wine was improved by treatment with $2.0 \mathrm{~g} / \mathrm{L}$ chitosan solution. Except for that of cyanidin-3-acetylhexoside, which increased by $2.43 \%$, the peak areas of the remaining seven anthocyanins all decreased to some extent during this process. Approximately $94.76 \%$ of the peonidin-3,5-dihexoside was lost, and the areas of the cyanidin-3-hexoside derivative, cyanidin-3,5-dihexoside, and peonidin-3-rutinoside peaks decreased by $43.06 \%, 56.10 \%$ and $52.33 \%$, respectively. However, lower losses (3.33\%-6.14\%) were found for peonidin-3-glucoside, cyanidin-3-glucoside and pelargonidin-3-glucoside.

Bottle ageing can significantly improve wine quality and overall aroma. In this study, the blue honeysuckle wine had a strong bouquet of wine and fruit flavour after ageing six months in brown glass bottles. The colour of the fruit wine gradually became yellow during the proces.

\subsection{Evolution of antioxidant activity at different stages of blue honeysuckle wine}

In this study, five common antioxidant assays (DPPH, ABTS, FRAP, TOAC, and CUPRAC) were used to evaluate the antioxidant activity at different stages. There are seven stages in the 
Table 3. Antioxidant capacity of samples in different processes.

\begin{tabular}{|c|c|c|c|c|c|c|c|}
\hline $\begin{array}{c}\text { Antioxidant } \\
\text { capacity assay }\end{array}$ & one & two & three & four & five & $\operatorname{six}$ & seven \\
\hline $\mathrm{DPPH}$ & $1.01 \pm 0.07^{\mathrm{D}}$ & $2.22 \pm 0.10^{\mathrm{B}}$ & $2.09 \pm 0.05^{\mathrm{C}}$ & $1.98 \pm 0.04^{\mathrm{C}}$ & $2.35 \pm 0.10^{\mathrm{A}}$ & $2.32 \pm 0.06^{\mathrm{AB}}$ & $2.00 \pm 0.05^{\mathrm{C}}$ \\
\hline ABTS & $20.15 \pm 1.10^{\mathrm{D}}$ & $59.93 \pm 1.52^{\mathrm{A}}$ & $55.93 \pm 3.36^{\mathrm{A}}$ & $41.63 \pm 2.30^{\mathrm{C}}$ & $38.48 \pm 2.05^{\mathrm{C}}$ & $38.72 \pm 3.79^{\mathrm{C}}$ & $47.12 \pm 1.50^{\mathrm{B}}$ \\
\hline FRAP & $154.07 \pm 4.76^{\mathrm{E}}$ & $379.63 \pm 16.61^{A}$ & $370.44 \pm 18.13^{\mathrm{A}}$ & $340.54 \pm 15.46^{\mathrm{B}}$ & $316.96 \pm 6.33^{\mathrm{BC}}$ & $307.88 \pm 20.54^{\mathrm{C}}$ & $247.05 \pm 11.63^{\mathrm{D}}$ \\
\hline TOAC & $27.68 \pm 5.75^{\mathrm{C}}$ & $40.18 \pm 1.94^{\mathrm{B}}$ & $132.25 \pm 5.65^{\mathrm{A}}$ & $10.08 \pm 0.02^{\mathrm{D}}$ & $9.49 \pm 0.24^{\mathrm{D}}$ & $9.43 \pm 0.17^{\mathrm{D}}$ & $10.15 \pm 0.08^{\mathrm{D}}$ \\
\hline CUPRAC & $1.12 \pm 0.11^{\mathrm{D}}$ & $6.34 \pm 0.21^{\mathrm{A}}$ & $5.84 \pm 0.27^{\text {B }}$ & $3.84 \pm 0.14^{\mathrm{C}}$ & $3.81 \pm 0.12^{\mathrm{C}}$ & $3.92 \pm 0.19^{\mathrm{C}}$ & $4.02 \pm 0.11^{\mathrm{C}}$ \\
\hline
\end{tabular}

Data are expressed as means \pm SD $(n=3)$. Different capital letters in line indicate significant differences $(P<0.05)$. DPPH, ABTS, TOAC, CUPRAC value were expressed as mg ascorbic acid/mL sample. FRAP value was expressed as $\mathrm{mmolF} \mathrm{e}^{2+} / \mathrm{mL}$ sample. One: Lonicera caerulea juice, two: Enzymatic hydrolysis, three: sugar and acid adjustments, four: fermentation, five: deacidification, six: clarification, seven: ageing

wine brewing process, namely, 1 blue honeysuckle juice (before enzymatic hydrolysis), 2 enzymatic hydrolysis, 3 sugar and acid adjustments, 4 fermentation, 5 deacidification, 6 clarification, 7 ageing. The antioxidant capacities of seven samples were determined, and the results are shown in Table 3.

The results are expressed as $\mathrm{mg}$ ascorbic acid/mL sample. The DPPH radical scavenging capacities of blue honeysuckle at different stages are shown in Table 3. The DPPH value of blue honeysuckle juice was $1.01 \pm 0.07 \mathrm{mg}$ ascorbic acid $/ \mathrm{mL}$ sample. Pectinase hydrolysis significantly increased the DPPH value of the sample. The DPPH value decreased upon sugar and acid adjustments and fermentation, but there was no significant difference between the sugar and acid adjustments and the fermentation sample. Surprisingly, the addition of calcium carbonate and sodium carbonate significantly increased the DPPH value. The DPPH values gradually decreased in the subsequent processes of clarification and ageing.

Using ascorbic acid as a standard, the results are expressed as $\mathrm{mg}$ ascorbic acid $/ \mathrm{mL}$ sample. The effects of different stages of winemaking on the ABTS values are shown in Table 3. The ABTS value of blue honeysuckle juice was $20.15 \pm 1.10 \mathrm{mg}$ ascorbic $\mathrm{acid} / \mathrm{mL}$, which is significantly lower than that of the enzymatically hydrolysed sample. The ABTS values tended to gradually decrease upon sugar and acid adjustments, fermentation and deacidification. There were no significant differences among the ABTS values of the fermentation, deacidification and clarification samples, and their values were $41.63 \pm 2.30,38.48 \pm 2.05$ and $38.72 \pm 3.79$, respectively. An ABTS value of $47.12 \pm 1.50$ value was found for aged blue honeysuckle wine, which is higher than that of clarified wine (38.72 \pm 3.79$)$. This phenomenon may be due to the appearance of some substances with ABTS free radical scavenging ability during the ageing process.

Different concentrations of $\mathrm{Fe}^{2+}$ were used as standards. The impacts of different processing steps on the FRAP values are shown in Table 3. Enzymatic hydrolysis can significantly increase the FRAP value, and thus the FRAP value of the sample following hydrolysis is higher than that of blue honeysuckle juice. In the subsequent processing steps, the FRAP values of the samples tended to decrease. However, a FRAP value of $247.05 \pm 11.63 \mathrm{mmol}$ $\mathrm{Fe}^{2+} / \mathrm{mL}$ sample was found in the aged wine, and this value is higher than that of blue honeysuckle juice, indicating that fermented wine still has a high antioxidant capacity.

A standard curve was drawn with different concentrations of ascorbic acid as the abscissa. As shown in Table 3, the TOAC value of blue honeysuckle juice was $27.68 \pm 5.75 \mathrm{mg}$ ascorbic acid $/ \mathrm{mL}$. Enzymatic hydrolysis and sugar and acid adjustments significantly increase the TOAC values. Fermentation significantly decreased the TOAC value. However, there were no significant differences among the samples following fermentation, deacidification, clarification and ageing.

In this study, the CUPRAC values are expressed as mg ascorbic acid/mL sample. Like other antioxidant indicators, pectinase hydrolysis can significantly enhance the copper ion reducing ability $(6.34 \pm 0.21)$. Acid and sugar adjustment significantly decreased the CUPRAC value (5.84 \pm 0.27$)$. The CUPRAC values were different following each of the subsequent four processes, but there were no significant differences among them.

\section{Conclusions}

Anthocyanins content of the wine depends on berry variety and maturation stage, climatic conditions, soil, winemaking protocols that influence their extraction rate and chemical reactions which take place during fermentation (including enzymatic and non-enzymatic oxidation) but also aging (Lorrain et al., 2013). The results obtained in this study showed that different processes in blue honeysuckle wine brewing have different effects on the anthocyanin content and composition and on the antioxidant activity. Because some anthocyanins are present in the skin of blue honeysuckle, the content of anthocyanins dissolved in Lonicera edulis juice is low, resulting in a lower antioxidant activity. Eight anthocyanins were found in the juice. The addition of pectinase significantly increased the anthocyanin content and the antioxidant capacity of the juice. The anthocyanin content and antioxidant capacity decreased significantly upon adjustment of the acid and sugar content and upon fermentation. Although the addition of calcium carbonate and sodium carbonate increased the total acid content in blue honeysuckle wine, decreasing the anthocyanin content, a superior DPPH radical scavenging capacity was found. Chitosan clarification had little effect on the anthocyanin content and antioxidant capacity of the wine. The aged wine samples had superior DPPH, ABTS, FRAP, TOAC and CUPRAC values. These results indicate that although the anthocyanins undergo some degradation during the brewing process, they still have a high antioxidant capacity. In the next step, the aged wine will be analyzed and determined for organic acids, flavonoids and polyphenols, and possible pathways for anthocyanin transformation will be established. 


\section{Reference}

Ayaz, F. A., Ozcan, M., Kurt, A., Karayigit, B., Ozogul, Y., Glew, R., \& Ozogul, F. (2017). Fatty acid composition and antioxidant capacity of cypselas in Centaureas.l. taxa (Asteraceae, Cardueae) from NE Anatolia. South African Journal of Botany, 112, 474-482. http:// dx.doi.org/10.1016/j.sajb.2017.06.033.

Bao, T., Xie, L. H., Xie, J. H., \& Chen, W. (2019). Phenolic composition of blue honeysuckle and its protective effect against oxidative damage following gastrointestinal digestion and gut microbiota fermentation. Abstracts of Papers of the American Chemical Society, 258, 275-AGFD.

Berenguer, M., Vegara, S., Barrajón, E., Saura, D., Valero, M., \& Martí, N. (2016). Physicochemical characterization of pomegranate wines fermented with three different Saccharomyces cerevisiae yeast strains. Food Chemistry, 190, 848-855. http://dx.doi.org/10.1016/j. foodchem.2015.06.027. PMid:26213048.

Boyarskikh, I. G., Chankina, O. V., \& Syso, A. I. (2016). SR XRF used to study the content of chemical elements in the leaves of Lonicera caerulea (Caprifoliaceae), depending on the change in seismic activity. Physics Procedia, 84, 275-279. http://dx.doi.org/10.1016/j. phpro.2016.11.047.

Caridi, A. (2007). New perspectives in safety and quality enhancement of wine through selection of yeasts based on the parietal adsorption activity. International Journal of Food Microbiology, 120(1-2), 167-172. http://dx.doi.org/10.1016/j.ijfoodmicro.2007.08.032. PMid:17888539.

Cassidy, A. (2017). Berry anthocyanins intake and cardiovascular health. Molecular Aspects of Medicine, 61, 76-82. http://dx.doi.org/10.1016/j. mam.2017.05.002. PMid:28483533.

Celli, G. B., Ghanem, A., \& Brooks, M. S.-L. (2015). Optimization of ultrasound-assisted extraction of anthocyanins from haskap berries (Lonicera caerulea L.) using Response Surface Methodology. Ultrasonics Sonochemistry, 27, 449-455. http://dx.doi.org/10.1016/j. ultsonch.2015.06.014. PMid:26186866.

Denev, P., Kratchanova, M., Ciz, M., Lojek, A., Vasicek, O., Nedelcheva, P., Blazheva, D., Toshkova, R., Gardeva, E., Yossifova, L., Hyrsl, P., \& Vojtek, L. (2014). Biological activities of selected polyphenol-rich fruits related to immunity and gastrointestinal health. Food Chemistry, 157, 37-44. http://dx.doi.org/10.1016/j.foodchem.2014.02.022. PMid:24679749.

Fischer, U. A., Carle, R., \& Kammerer, D. R. (2013). Thermal stability of anthocyanins and colourless phenolics in pomegranate (Punica granatum L.) juices and model solutions. Food Chemistry, 138(23), 1800-1809. http://dx.doi.org/10.1016/j.foodchem.2012.10.072. PMid:23411312.

Gawronski, J., Żebrowska, J., Pabich, M., Jackowska, I., Kowalczyk, K., \& Dyduch-Siemińska, M. (2020). Phytochemical Characterization of blue honeysuckle in relation to the genotypic diversity of Lonicerasp. Applied Sciences-Basel, 10(18), xx-xx.

Gorinstein, S., Caspi, A., Libman, I., \& Trakhtenberg, S. (2000). Mechanism of cardioprotective effect and the choice of alcoholic beverage. The American Journal of Cardiology, 85(2), 280-281. http://dx.doi.org/10.1016/S0002-9149(99)00899-1. PMid:10955396.

Grobelna, A., Kalisz, S., \& Kieliszek, M. (2019). Effect of processing methods and storage time on the content of bioactive compounds in Blue Honeysuckle Berry Purees. Agronomy (Basel), 9(12), 860. http://dx.doi.org/10.3390/agronomy9120860.

Guo, J., Yan, Y., Wang, M., Wu, Y., Liu, S.-Q., Chen, D., \& Lu, Y. (2018). Effects of enzymatic hydrolysis on the chemical constituents in jujube alcoholic beverage fermented with Torulaspora delbrueckii. Lebensmittel-Wissenschaft + Technologie, 97, 617-623. http://dx.doi. org/10.1016/j.lwt.2018.07.051.
Jennings, A., Welch, A. A., Fairweather-Tait, S. J., Kay, C., Minihane, A.-M., Chowienczyk, P., Jiang, B., Cecelja, M., Spector, T., Macgregor, A., \& Cassidy, A. (2012). Higher anthocyanins intake is associated with lower arterial stiffness and central blood pressure in women. The American Journal of Clinical Nutrition, 96(4), 781-788. http:// dx.doi.org/10.3945/ajcn.112.042036. PMid:22914551.

Kruger, M. J., Davies, N., Myburgh, K. H., \& Lecour, S. (2014). Proanthocyanidins, anthocyanins and cardiovascular diseases. Food Research International, 59, 41-52. http://dx.doi.org/10.1016/j. foodres.2014.01.046.

Lee, J. C., Dreves, A. J., Cave, A. M., Kawai, S., Isaacs, R., Miller, J. C., Van Timmeren, S., \& Bruck, D. J. (2015). Infestation of Wild and Ornamental Noncrop Fruits by Drosophila suzukii (Diptera: Drosophilidae). Annals of the Entomological Society of America, 108(2), 117-129. http://dx.doi.org/10.1093/aesa/sau014.

Li, J. B., Hashimoto, F., Shimizu, K., \& Sakata, Y. (2009). A new acylated anthocyanin from the red flowers of Camellia hongkongensis and characterization of anthocyanins in the section Camellia species. Journal of Integrative Plant Biology, 51(6), 545-552. http://dx.doi. org/10.1111/j.1744-7909.2009.00828.x.

Liu, C., Zheng, X., Jia, S., Ding, N., \& Gao, X. (2009). Comparative experiment on hotair and microwave-vacuum drying and puffing of blue honeysuckle snack. International Journal of Food Engineering, 5(4), 1-9. http://dx.doi.org/10.2202/1556-3758.1683.

Liu, C., Zheng, X., Shi, J., Xue, J., Lan, Y., \& Jia, S. (2010). Optimising microwave vacuum puffing for blue honeysuckle snacks. International Journal of Food Science \& Technology, 45(3), 506-511. http://dx.doi. org/10.1111/j.1365-2621.2009.02156.x.

Lorrain, B., Ky, I., Pechamat, L., \& Teissedre, P. L. (2013). Evolution of analysis of polyhenols from grapes, wines, and extracts. Molecules (Basel, Switzerland), 18(1), 1076-1100. http://dx.doi.org/10.3390/ molecules18011076. PMid:23325097.

Mason, J. (2013). Bryce Rankine: Wine scientist. Chemistry in Australia, 2013, 30-31.

Medina, K., Boido, E., Dellacassa, E., \& Carrau, F. (2005). Yeast Interactions with anthocyanins during Red Wine Fermentation. Journal of Enology and Viticulture, 56, 104-109.

Myjavcová, R., Marhol, P., Kren, V., Šimánek, V., Ulrichová, J., Palíková, I., Papoušková, B., Lemr, K., \& Bednář, P. (2010). Analysis of anthocyanins pigments in Lonicera (Caerulea) extracts using chromatographic fractionation followed by microcolumn liquid chromatography-mass spectrometry. Journal of Chromatography. A, 1217(51), 7932-7941. http://dx.doi.org/10.1016/j.chroma.2010.05.058. PMid:21111888.

Pascual-Teresa, S. D. (2014). Molecular mechanisms involved in the cardiovascular and neuroprotective effects of anthocyanins. Archives of Biochemistry and Biophysics, 559, 68-74. http://dx.doi.org/10.1016/j. abb.2014.04.012. PMid:24791600.

Pereira-Caro, G., Clifford, M. N., Polyviou, T., Ludwig, I. A., Alfheeaid, H., Moreno-Rojas, J. M., Garcia, A. L., Malkova, D., \& Crozier, A. (2020). Plasma pharmacokinetics of (poly)phenol metabolites and catabolites after ingestion of orange juice by endurance trained men. Free Radical Biology \& Medicine, 160, 784-795. http://dx.doi. org/10.1016/j.freeradbiomed.2020.09.007.

Prieto, M. A., Vazquez, J. A., \& Murado, M. A. (2015). Crocin bleaching antioxidant assay revisited: application to microplate to analyse antioxidant and pro-oxidant activities. Food Chemistry, 167, 299310. http://dx.doi.org/10.1016/j.foodchem.2014.06.114.

Qiu, J. Q., Zhang, H., Wang, Z., Liu, S., \& Regenstein, J. M. (2016). Response Surface Methodology for the Synthesis of an Auricularia Auriculajudae Polysaccharides-CDDP Complex. International 
Journal of Biological Macromolecules, 93(Pt A), 333-343. http:// dx.doi.org/10.1016/j.ijbiomac.2016.06.066. PMid:27343707.

Santhakumar, A. B., Kundur, A. R., Fanning, K., Netzel, M., Stanley, R., \& Singh, I. (2015). Consumption of anthocyanins-rich Queen Garnet plum juice reduces platelet activation related thrombogenesis in healthy volunteers. Journal of Functional Foods, 12, 11-22. http:// dx.doi.org/10.1016/j.jff.2014.10.026.

Scutarasu, E.-C., Luchian, C. E., Vlase, L., Colibaba, L. C., Gheldiu, A. M., \& Cotea, V. V. (2021). Evolution of phenolic profile of white wines treated with enzymes. Food Chemistry, 340, 340. http://dx.doi. org/10.1016/j.foodchem.2020.127910. PMid:32882475.

Sharma, A., \& Lee, H. J. (2021). Lonicera caerulea: An updated account of its phytoconstituents and health-promoting activities. Trends in Food Science \& Technology, 107, 130-149. http://dx.doi.org/10.1016/j. tifs.2020.08.013.

Shen, Y.-B., Song, X., Chen, Y.-S., Li, L., Sun, J., Huang, C.-H., Ou, S.-Y., \& Zhang, H. (2017). Effects of sorghum, purple rice and rhubarb rice on lipids status and antioxidant capacity in mice fed a high-fat diet. Journal of Functional Foods, 39, 103-111. http://dx.doi. org/10.1016/j.jff.2017.10.017.

Skupien, K., Oszmiański, J., Ochiman, I., Grajkowski, J. (2007). Characterization of selected physicochemical features of blue honeysuckle fruit cultivar Zielona. Polish Journal of Natural Sciences, $4,101-107$.

Svobodová, A., Zdarilová, A., \& Vostálova, J. (2009). Lonicera caerulea and Vaccinium myrtillus fruit polyphenols protect $\mathrm{HaCaT}$ keratinocytes against UVB-induced phototoxic stress and DNA damage. Journal of Dermatological Science, 56(3), 196-204. http://dx.doi.org/10.1016/j. jdermsci.2009.08.004. PMid:19747801.

Toy, J. Y. H., Lu, Y., Huang, D., Matsumura, K., \& Liu, S. Q. (2020). Enzymatic treatment, unfermented and fermented fruit-based products: current state of knowledge. Critical Reviews in Food Science and Nutrition, 1-22. http://dx.doi.org/10.1080/10408398.2 020.1848788. PMid:33249876.

Veberic, R., Slatnar, A., Bizjak, J., Stampar, F., \& Petkovsek, M. M. (2015). anthocyanins composition of different wild and cultivated berry species. Food Science and Technology (Campinas), 60(1), 509-517.
Vilkickyte, G., Raudone, L., \& Petrikaite, V. (2020). Phenolic Fractions from Vaccinium vitis-idaea $L$. and Their Antioxidant and Anticancer Activities Assessment. Antioxidants, 9(12), 1261. http://dx.doi. org/10.3390/antiox9121261. PMid:33322638.

Wang, Y.-H., Li, B., Lin, Y., Ma, Y., Zhang, Q., \& Meng, X.-J. (2017). Effects of Lonicera caerulea berry extract on lipopolysaccharideinduced toxicity in rat liver cells: Antioxidant, anti-inflammatory, and anti-apoptotic activities. Journal of Functional Foods, 33, 217226. http://dx.doi.org/10.1016/j.jff.2017.03.041.

Wang, Y.-H., Li, B., Ma, Y., Wang, X.-Y., Zhang, X.-Y., Zhang, Q., \& Meng, X.-J. (2016b). Lonicera caerulea berry extract attenuates lipopolysaccharide induced inflammation in BRL-3A cells: Oxidative stress, energy metabolism, hepatic function. Journal of Functional Foods, 24, 1-10. http://dx.doi.org/10.1016/j.jff.2016.03.023.

Wang, Y.-H., Zhu, J.-Y., Meng, X.-J., Liu, S.-W., Mu, J.-J., \& Ning, C. (2016a). Comparison of polyphenol, anthocyanins and antioxidant capacity in four varieties of Lonicera caerulea berry extracts. Food Chemistry, 197(Pt A), 522-529. http://dx.doi.org/10.1016/j. foodchem.2015.11.006. PMid:26616984.

Wu, S., Yano, S., Hisanaga, A., He, X., He, J., Sakao, K., \& Hou, D. X. (2017). Polyphenols from Lonicera caerulea L. berry attenuate experimental nonalcoholic steatohepatitis by inhibiting proinflammatory cytokines productions and lipid peroxidation. Molecular Nutrition \& Food Research, 61(4), 1770044. http://dx.doi.org/10.1002/mnfr.201770044. PMid:27935258.

Zdarilova, A., Svobodova, A., Chytilová, K., Šimánek, V., \& Ulrichová, J. (2010). Polyphenolic fraction of Lonicera caerulea L. fruits reduces oxidative stress and inflammatory markers induced by lipopolysaccharide in gingival fibroblasts. Food and Chemical Toxicology, 48(6), 15551561. http://dx.doi.org/10.1016/j.fct.2010.03.024. PMid:20332009.

Zhang, J. T., Sun, L. J., Dong, Y., Fang, Z., Nisar, T., Zhao, T., Wang, Z. C., \& Guo, Y. (2019). Chemical compositions and alpha-glucosidase inhibitory effects of anthocyanidins from blueberry, blackcurrant and blue honeysuckle fruits. Food Chemistry, 299, 299. http://dx.doi. org/10.1016/j.foodchem.2019.125102. PMid:31279126.

Zheng, G. Q., Deng, J., Wen, L., You, L., Zhao, Z., \& Zhou, L. (2018). Release of phenolic compounds and antioxidant capacity of Chinese hawthorn "Crataegus pinnatifida" during in vitro digestion. Journal of Functional Foods, 40, 76-85. http://dx.doi.org/10.1016/j.jff.2017.10.039. 